\title{
Intracranial hypotension secondary to spontaneous spinal cerebrospinal fluid leaks
}

Hipotensão intracraniana secundária a fístula liquórica espinhal espontânea

Antonio Eustáquio Silva Junior', Patricia Pavan², Mariana Mari Oshima', Tânia Marchiori de Oliveira Cardoso ${ }^{2}$, Fabiano Reis ${ }^{1}$

A 37-year-old woman presented with acute orthostatic hypotension and diffuse headache. Brain magnetic resonance imaging (MRI) revealed T2 hyperintense bilateral subdural effusions, diffuse pachymeningeal enhancement, slit ventricles and venous engorgement compatible with spontaneous intracranial hypotension. Single photon emission computed tomography with computed tomography (CT) and CT-cisternography showed a cerebrospinal fluid (CSF) leak at the left C1-C2 transition. Spontaneous intracranial hypotension is a rare cause of daily headache, which remains largely underdiagnosed $^{1,2}$, and current evidence indicates that this condition is the result of a spontaneous CSF leak ${ }^{1,2,3,4}$. This case illustrates the importance of CT-cisternography in the detection of CFS leak ${ }^{1,2,3}$, allowing appropriate diagnosis and treatment.
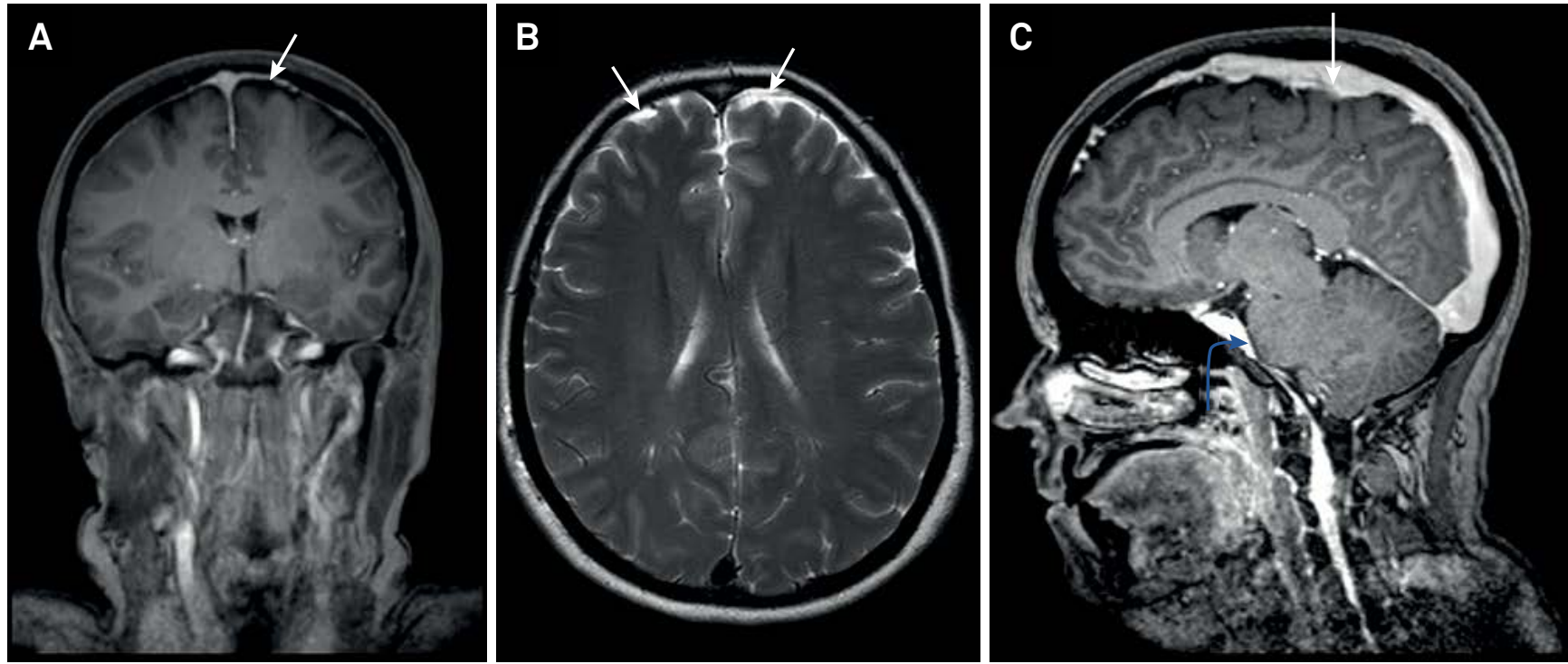

Figure 1. Coronal T1 post contrast MRI demonstrates pachymeningeal enhancement (arrows); (B) axial T2 weighted MRI demonstrates subdural effusions (arrows); (C) Sagittal T1-weighted post contrast demonstrates engorgement of the superior sagittal sinus (straight arrow) and sagging of the brain (flattening of the pons and obliteration of prepontine cistern, curved arrow).

${ }^{1}$ Universidade Estadual de Campinas, Faculdade de Ciências Médicas, Departamento de Radiologia, Campinas SP, Brasil; ${ }^{2}$ Universidade Estadual de Campinas, Faculdade de Ciências Médicas, Departamento de Neurologia, Campinas SP, Brasil. Correspondence: Fabiano Reis; Faculdade de Ciências Médicas - UNICAMP, Departamento de Radiologia; Rua Tessália Vieira de Camargo, 126 , Cidade Universitária Zeferino Vaz; 13083-887 Campinas SP, Brasil, E-mail: fabianoreis2@gmail.com Conflict of interest: There is no conflict of interest to declare. Received 20 January 2016; Accepted 03 October 2016. 

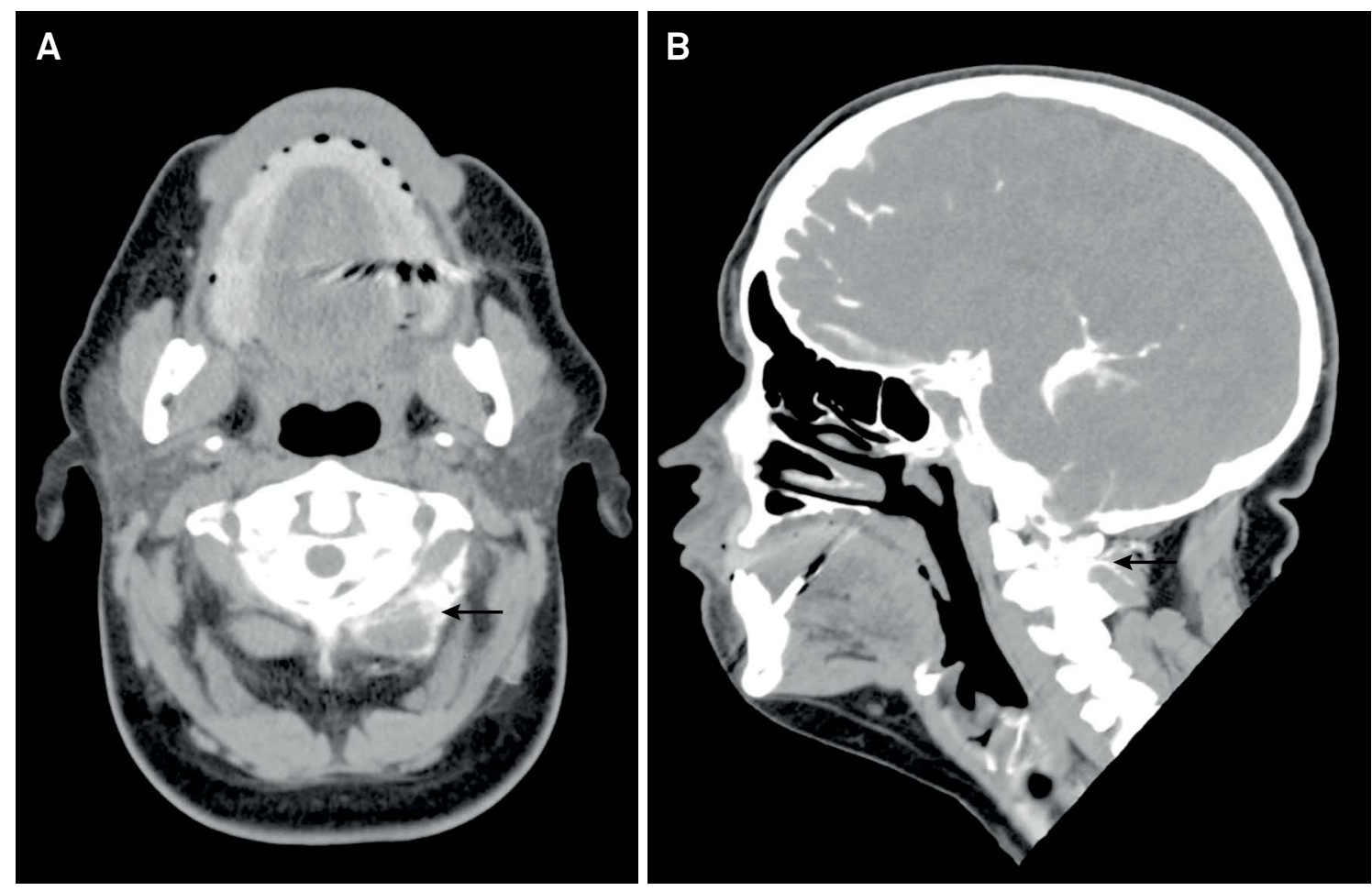

Figure 2. Sagittal and axial sections of CT-cisternography (A) axial and (B) sagittal show a C1-C2 left cerebrospinal fluid leak, with left fluid paravertebral collection (arrows).

\section{References}

1. Schievink WI. Spontaneous spinal cerebrospinal fluid leaks. Cephalalgia. 2008;28(12):1347-56. https://doi.org/10.1111/j.1468-2982.2008.01776.x

2. Purdy RA. Understanding and managing spontaneous intracranial hypotension. Can J Neurol Sci. 2013;40(2):139-40. https://doi.org/10.1017/S0317167100013640
3. Mokri B. Spontaneous intracranial hypotension. Continuum (Minneap Minn). 2015;21(4 Headache):1086-108.

4. Hoffmann J, Goadsby PJ. Update on intracranial hypertension and hypotension. Curr Opin Neurol. 2013;26(3):240-7. https://doi.org/10.1097/WC0.0b013e328360eccc 